\title{
O direito à saúde no Brasil: da redemocratização constitucional ao neoliberalismo de exceção dos tempos atuais
}

The right to health in Brazil: from the 1988 democratization to the neoliberalism of exception of the present times

El derecho a la salud en Brasil: de la redemocratización constitucional al neoliberalismo de excepción de los tiempos actuales

Jarbas Ricardo Almeida Cunha

RESUMO: Objetivo - Delinear o histórico juspolítico do Direito à Saúde no Brasil em quatro fases da Nova República, desde sua redemocratização dos anos 1980 até a conjuntura constitucional hodierna. Metodologia - Utiliza-se a revisão de literatura de tipo narrativa com a finalidade de analisar o estado da arte do Direito à Saúde no Brasil. Resultados - O histórico juspolítico do Direito à Saúde constitucionalizado no Brasil é influenciado por uma disputa ideopolítica que fornece como resultado alguns avanços e muitos retrocessos em relação ao projeto do SUS Constitucional. Conclusão - É preciso recolocar na pauta nacional a defesa da efetivação do Direito à Saúde no Brasil, afirmando os objetivos, princípios e diretrizes do Sistema Único de Saúde.

Palavras-Chave: Direito à Saúde. Sistema Único de Saúde. Democracia.

ABSTRACT: Objective - By dividing the recent history in four phases from the 1988 democratization to the present, the paper aims to explore the legal and political aspects of describe the Right to Health in Brazil. . Methods - A narrative literature review is used to organize the development of the debate about the Right to Health in Brazil. Results - From a historic standpoint, the legal and political aspects of the Constitutional Right to Health in Brazil is influenced by an ideologic dispute that results in a few advances and many setbacks in relation to the original Constitutional Project of SUS. Conclusion - It is necessary to reinforce a national agenda for the defense of the Right to Health in Brazil, one which affirms the objectives, principles and guidelines of the Unified Public Health System.

Keywords: Right to Health. Unified Health System. Democracy.

RESUMEN: Objetivo - Delinear el histórico juspolítico del Derecho a la Salud en Brasil en cuatro fases de la Nueva República, desde su redemocratización de los años 1980 hasta la coyuntura constitucional actual. Metodología - Se utiliza la revisión de literatura de tipo narrativa con la finalidad de analizar el estado del arte del Derecho a la Salud en Brasil. Resultados - El histórico juspolítico del Derecho a la Salud constitucionalizado en Brasil es influenciado por una disputa ideopolítica que proporciona como resultado algunos avances y muchos retrocesos en relación al proyecto del SUS Constitucional. Conclusión - Es necesario volver a colocar en la pauta nacional la defensa de la efectividad del Derecho a

Doutorando em Direito, Estado e Constituição pela Universidade de Brasília (UnB). Graduação em Direito pela Universidade Federal de Ouro Preto - UFOP, especialização em Direito Sanitário pela Fundação Oswaldo Cruz - Fiocruz e Mestrado em Política Social pela Universidade de Brasília - UnB. Núcleo de Saúde - Defensoria Pública da União (DPU/RS). E-mail: jarbas.ricardo@yahoo.com.br. 
la Salud en Brasil, afirmando los objetivos, principios y directrices del Sistema Único de Salud.

Palabras-clave: Derecho a la Salud. Sistema Único de Salud. Democracia.

\section{Introdução}

Este artigo se propõe a sistematizar e a analisar o percurso do Direito à Saúde em nosso país, desde a instauração do Sistema Único de Saúde (SUS) constitucional até a atualidade de um SUS Pós-Constitucional, destacando seus avanços democráticos e participativos permeados por retrocessos institucionais em seu permanente exercício de efetivação na sociedade brasileira.

Pretende-se neste trabalho percorrer o histórico juspolítico de formação do Direito à Saúde no Brasil analisando quatro fases: a) o período da redemocratização constitucional dos anos 1980; b) o neoliberalismo clássico dos anos 1990; c) os anos de auge e declínio dos governos do Partido dos Trabalhadores nos anos 2000 e; d) os tempos atuais do neoliberalismo de exceção.

Para cumprirmos com a finalidade deste artigo, utilizaremos a metodologia da revisão de literatura de tipo narrativa, em que consiste relatar "publicações amplas, apropriadas para descrever e discutir o desenvolvimento ou o 'estado da arte' de um determinado assunto, sob ponto de vista teórico ou contextual" (1).

Nesta revisão narrativa, utiliza-se livros, artigos científicos, doutrina, jurisprudência e um conjunto de normativos, além de alguns documentos jurídicos, sempre em uma tentativa de análise crítica pessoal do autor.

\section{Os anos 1980: redemocratização, reforma sanitária brasileira e constitucionalização do direito à saúde}

\section{A redemocratização e o movimento da reforma sanitária brasileira}

Antes da promulgação da Constituição de 1988 - em que pesem tímidos avanços institucionais - as políticas públicas de saúde tinham como objetivo principal propiciar a manutenção e recuperação da força de trabalho necessárias à reprodução social do capital e, dialogando com este modelo, o setor sanitário brasileiro era marcado por forte cunho assistencialista e curativo, de caráter crescentemente privatista, sem prioridade para políticas públicas de saúde com sentido de universalidade, integralidade e equidade. 
Para mudar esse quadro no Brasil, os Departamentos de Medicina Preventiva (DMP's) $^{2}$ foram o principal instrumento de apoio para a criação do movimento sanitário com o intuito de unir a teoria à prática da política de saúde em um direcionamento preventivista, de forma dialética, apreendendo os aspectos e contextos políticos, econômicos, sociais e culturais que abarcavam a saúde de forma direta e indireta na política pública.

Nos anos 1970, em plena ditadura militar ${ }^{3}$, havia três correntes do pensamento sanitário no ambiente dos DMP's : 1) liberal, caracterizado pela defesa da suposta neutralidade da ciência, com foco no indivíduo e prevalência do setor privado; 2) racionalizador, que almejava uma interação entre a gestão institucionalizada via secretarias de saúde com universidades de pensamento crítico para sintetizar uma proposta viável de saúde pública para a população e; 3) médico-social, com pensamento heterodoxo e de enfrentamento à situação vigente, propondo a teoria como instrumento de luta política, o processo saúde-doença como totalidade, delimitação do campo da saúde coletiva, desmedicalização e controle popular, demandas combinadas com a luta pelo reestabelecimento democrático (2).

Nesse período, a ditadura militar se encontrava numa crise de legitimidade e precisava implementar políticas públicas de saúde para amenizar as desigualdades causadas principalmente pelos anos de chumbo ${ }^{4}$ e seu falacioso milagre econômico ${ }^{5}$. Nesta brecha aberta pelo Estado, ativistas sanitários começaram a ocupar postos estratégicos para que, utilizando uma postura gramsciana ${ }^{6}$, influenciasse de dentro para

\footnotetext{
2 Os DMP's foram criados na década de 1950 e se consolidaram com a Lei da Reforma Universitária de 1968 (Lei nº 5.540, de 28 de novembro de 1968) que, apesar de seu caráter ditatorial e repressivo, tornou a criação dos DMP's obrigatória nas universidades brasileiras. Por uma ironia da história, o ambiente dos DMP's serviu de laboratório para o Movimento da Reforma Sanitária Brasileira nos anos 1970 e, principalmente, com a redemocratização dos anos 1980. Atualmente, a Lei da Reforma Universitária encontra-se revogada pela Lei de Diretrizes e Bases da Educação Brasileira (LDB) - Lei no 9.394, de 20 de dezembro de 1996.

${ }^{3}$ Não utilizo o termo ditadura civil-militar, ultimamente bem difundido, pois receio a diluição da expressão ditadura militar, já que no período (1964-1985) o alto comando das forças armadas ocupava todo o aparato da estrutura e superestrutura do Estado sendo responsável direto pelos crimes de lesa-humanidade - torturas, execuções, desaparecimentos etc.

4 "Anos de Chumbo" refere-se ao período de maior repressão e endurecimento da ditadura militar, geralmente entre a edição do Ato Institucional no 5 (Al-5), de 13 de dezembro de 1968 até o fim do Governo Médici em 1974.

${ }^{5}$ Período que coincidiu com os anos de chumbo (1968-1974) em que o PIB brasileiro cresceu entre $9,8 \%(1968)$ e $13,6 \%$ (1973). E, que, segundo Cunha (2016) demonstrou “...não ter havido coincidência entre o aumento das taxas de crescimento econômico com extrema desigualdade social e o aumento das prisões, torturas e assassinatos cometidos pela Ditadura de Estado..." (p. 31).

${ }^{6}$ Antônio Gramsci (1891-1937), pensador e militante marxista revolucionário italiano e uma das maiores influências da Reforma Sanitária, acreditava na disputa da hegemonia por dentro do aparelho da superestrutura do Estado, em uma tentativa de consolidação de sua influência ideológica perante a sociedade civil. Muito simplificadamente, essa descrição é a tal "postura gramsciana" a qual me refiro.
} 
fora ("centrifugamente") a lógica de atuação estatal. Essa tática obteve bastante êxito com programas como o Projeto Montes Claros (MOC) e o Programa de Interiorização das Ações de Saúde e Saneamento (Piass).

O Projeto Montes Claros (MOC) foi implementado no início da década de 1970 na cidade de mesmo nome situada no norte de Minas Gerais, e pode-se dizer que foi o precursor do Sistema Único de Saúde (SUS) pois sua atuação era realizada de forma descentralizada, regionalizada, hierarquizada, com administração democrática e eficiente com participação popular, integralidade de assistência sanitária e atendimento por auxiliares de saúde. O MOC foi uma escola de quadros para o que viria a ser o movimento de Reforma Sanitária brasileiro (3).

Já o Programa de Interiorização das Ações de Saúde e Saneamento (Piass) ${ }^{7}$, elaborado pelo setor de saúde do Instituto de Pesquisa Econômica e Aplicada (IPEA), objetivava a interiorização sanitária por meio dos programas de extensão propostos pela Organização Panamericana da Saúde (OPAS). Sua atuação estava centrada principalmente nos grotões do país, onde não havia interesse do mercado privado de saúde. Continha diretrizes parecidas com as do MOC, como universalização, descentralização, acessibilidade, integralidade e participação comunitária. Instalava rede de minipostos contratando auxiliares da saúde das próprias regiões atendidas. Podemos considerar que o Piass foi precursor do Conselho Nacional de Secretários Estaduais de Saúde (CONASS) (4).

Esse acúmulo de atuação contribuiu para a origem do Movimento pela Reforma Sanitária Brasileira (RSB), com toda a dinâmica de luta característica de movimento social, assumido por intelectuais-militantes como Sérgio Arouca ${ }^{8}$ e David Capistrano Filho ${ }^{9}$, por trabalhadores, usuários e gestores da saúde coletiva; artistas, ativistas e partidos políticos

\footnotetext{
7 O Piass foi consolidado, ampliado e expandido a todo território nacional com a publicação do Decreto ํㅜ 84.219, de 14 de novembro de 1979. Disponível em http://www2.camara.leg.br/legin/fed/decret/1970-1979/decreto-84219-14-novembro1979-433518-publicacaooriginal-1-pe.html Acesso em 16 de junho de 2017.

8 Sérgio Arouca (1941-2003) foi um dos maiores nomes da Reforma Sanitária Brasileira, tendo atuação não somente no Brasil mas em vários países da América Latina, influenciando e influenciado pelos sistemas de saúde mais progressistas da época, a exemplo do sistema cubano. Foi um dos maiores sistematizadores e ideólogos da Saúde Coletiva brasileira e do Sistema Único de Saúde - SUS, além de professor da Escola Nacional de Saúde Pública (ENSP), presidente da Fundação Oswaldo Cruz (Fiocruz) e político de alta envergadura em defesa do Direito à Saúde.

9 David Capistrano Filho (1948-2000) também foi grande líder da consolidação da Reforma Sanitária Brasileira, desenvolvendo ações sanitárias importantes enquanto secretário de saúde e, consequentemente, prefeito da cidade de Santos no final da década de 1980, dando impulso à ideias matriciais do SUS. Implementou uma gestão exemplar, como a campanha pela conscientização e prevenção sobre o vírus HIV, o programa de combate à cárie infantil, a atuação em prol da Reforma Psiquiátrica, a importância de se ter um orçamento sanitário robusto, enfim, ações e modelos de gestão que se tornaram referências para a afirmação do SUS em nosso país.
} 
constituindo-se numa ideia-síntese que se fortaleceu no final da década de 1970 e, principalmente, no decorrer da década de 1980, com a luta pela redemocratização.

No impulso deste movimento de liberdade e contestação surgiram diversos grupos sociais que ratificaram a luta pela saúde como as já históricas entidades do Centro Brasileiro de Estudos de Saúde (CEBES) ${ }^{10}$, em 1976 e a Associação Brasileira de PósGraduação em Saúde (ABRASCO) ${ }^{11}$, em 1979, acentuando o debate político-ideológico sobre as pautas e demandas da política pública de saúde em prol da sociedade brasileira.

Seguindo a mesma toada, com a conjuntura pró-redemocratização do Brasil nos anos 1980, iniciam-se consideráveis avanços na participação popular, como a criação do Sistema Unificado e Descentralizado da Saúde (SUDS) ${ }^{12}$ e, em 1986, o Movimento pela Reforma Sanitária conseguiu uma importante vitória com a realização da 8ª Conferência Nacional da Saúde (CNS), ocasião em que foi debatida não só a importância de um Sistema Único de Saúde (SUS), mas também um debate mais amplo em torno de uma Reforma Sanitária, com a constitucionalização do direito à saúde (5).

A 8a Conferência Nacional da Saúde (CNS) foi realizada em Brasília e contou com a presença de quatro mil pessoas sendo o evento institucional de maior relevância durante o período da denominada Nova República (6). O documento final foi resultado de três dias de debate nos 135 grupos de trabalho (38 de delegados e 97 de participantes), discutindo a seguinte temática e seus desdobramentos: saúde como direito, reformulação do Sistema Nacional de Saúde (resultando posteriormente no SUS) e financiamento/fundo público (7).

A Assembleia Nacional Constituinte realizada entre 1987 e 1988 equalizou as demandas da 8 a CNS em uma disputa ideológica que refletia, nas peculiaridades de um país de modernização conservadora (8), a influência do Estado do Bem Estar Social europeu e os conflitos ideopolíticos fomentados pelos progressistas e pelo "Centrão"13. Tal imbróglio democrático originou um sistema de seguridade social híbrido (9), pois

\footnotetext{
${ }^{10}$ Conferir em http://cebes.org.br/ Disponível em 22 de junho de 2017.

11 Conferir em https://www.abrasco.org.br/site/ Disponível em 22 de junho de 2017.

12 O Programa de Desenvolvimento de Sistemas Unificados e Descentralizados de Saúde nos Estados (SUDS) foram criados pelo Decreto no 94.657, de 20 de julho de 1987 se consolidando como uma proposta de descentralização das ações da política pública de saúde, adotando como diretrizes a universalização e a equidade no acesso aos serviços, integralidade dos cuidados, regionalização dos serviços de saúde, implementação de distritos sanitários, instituições colegiadas gestoras e política de recursos humanos. Disponível em http://www2.camara.leg.br/legin/fed/decret/19801987/decreto-94657-20-julho-1987-445419-publicacaooriginal-1-pe.html Acesso em 11 de junho de 2017.

${ }^{13}$ Segundo o Centro de Pesquisa e Documentação de História Contemporânea do Brasil (CPDOC) da Fundação Getúlio Vargas (FGV) o termo Centrão corresponde a "grupo suprapartidário com perfil de centro e direita criado no final do primeiro ano da Assembleia Nacional Constituinte de 1987-1988 para dar apoio ao presidente José Sarney. " Disponível em http://www.fgv.br/cpdoc/acervo/dicionarios/verbete-tematico/centrao Acesso em 11 de junho de 2017.
} 
sistematizada com direitos universais (saúde), dependentes do trabalho (previdência) e seletivos (assistência), não se consolidando como uma política de integração e unificação entre esses direitos constitucionalizados.

\section{A constitucionalização do direito à saúde no Brasil}

Passando a uma análise juspolítica da questão, especificamente em relação à constitucionalização do Direito à Saúde, o texto constitucional conseguiu abarcar o direito sanitário de uma forma mais geral e ampliada, tentando se aliar à sintonia da população e aos anseios do debate em torno do Movimento Sanitário com seus variados matizes.

Já no art. 1ํ, inciso III, da Constituição Federal se inicia a proteção constitucional do direito à saúde, corolário do direito à vida com a dignidade da pessoa humana como fundamento da República Federativa do Brasil ${ }^{14}$, que, por sua vez, é complementado pelo inciso IV do art. 3ำ que constitui como objetivo desta República a promoção do bem de todos $^{15}$. No art. $5^{\circ}$ há a inviolabilidade do direito à vida ${ }^{16} \mathrm{e}$, finalmente, no art. $6^{\circ}$, o direito à saúde é expressamente garantido dentre os direitos sociais ${ }^{17}$.

Outro artigo importante em nossa Carta Magna é o art. 196 que prescreve a saúde como direito de todos e dever do Estado, indicando ao Poder Público o caminho para assegurá-lo: "mediante políticas sociais e econômicas que visem à redução do risco de doença e de outros agravos e ao acesso universal e igualitário às ações e serviços para sua promoção, proteção e recuperação"18.

Um aspecto relevante e que envolve a participação dos entes federativos diz respeito às competências comuns e concorrentes. O art. 23, inciso II, relata que o dever de cuidar da saúde e da assistência pública é de competência comum da União, dos Estados, do

\footnotetext{
14 "Art. $1^{\circ} \mathrm{A}$ República Federativa do Brasil, formada pela união indissolúvel dos Estados e Municípios e do Distrito Federal, constitui-se em Estado Democrático de Direito e tem como fundamentos: III - a dignidade da pessoa humana; "(grifo nosso).

15“Art. $3^{\circ}$ Constituem objetivos fundamentais da República Federativa do Brasil: IV - promover o bem de todos, sem preconceitos de origem, raça, sexo, cor, idade e quaisquer outras formas de discriminação." (grifo nosso).

16 "Art. $5^{\circ}$ Todos são iguais perante a lei, sem distinção de qualquer natureza, garantindo-se aos brasileiros e aos estrangeiros residentes no País a inviolabilidade do direito à vida, à liberdade, à igualdade, à segurança e à propriedade, nos termos seguintes: " (grifo nosso).

17 "Art. $6^{\circ}$ São direitos sociais a educação, a saúde, a alimentação, o trabalho, a moradia, o transporte, o lazer, a segurança, a previdência social, a proteção à maternidade e à infância, a assistência aos desamparados, na forma desta Constituição. (grifo nosso).

18 "Art. 196. A saúde é direito de todos e dever do Estado, garantido mediante políticas sociais e econômicas que visem à redução do risco de doença e de outros agravos e ao acesso universal e igualitário às ações e serviços para sua promoção, proteção e recuperação. "
} 
Distrito Federal e dos Municípios ${ }^{19}$, enquanto o art. 24, inciso XII, delimita a competência concorrente da União, Estados e Distrito Federal para legislar sobre proteção e defesa da saúde 20 .

Outro ponto importante dado pela nossa Constituição ao direito à saúde é seu aspecto de relevância pública (art. 197, CF/88) 21 . A relevância pública abarca os objetivos e fundamentos que dão lastro à aplicação das políticas públicas conforme a República Federativa do Brasil, e que estão consolidados nos art. $1^{\circ}$ e $3^{\circ}$ de nossa Carta Política de 1988 como, por exemplo, a dignidade da pessoa humana, a construção de uma sociedade justa, livre e solidária, a promoção do bem comum e a erradicação da pobreza. A efetivação do direito à saúde, principalmente no contexto brasileiro, é uma luta constante para garantir e avançar nesses objetivos e fundamentos da República, portanto, não há dúvida que o direito à saúde é um direito de relevância pública (10).

O procurador da República Marlon Weichert (11) ratifica essa qualificação de relevância pública ao interpretar que a saúde, dentre os direitos sociais, é prioritária, não devendo ser menosprezado frente aos demais, principalmente em relação à destinação de recursos financeiros. À saúde deve ser assegurado um financiamento que corresponda à sua relevância em comparação com outros direitos, estes sendo civis, econômicos, políticos ou até mesmo sociais. O direito à saúde deve ser priorizado no orçamento público pelo fato de ser classificado, constitucionalmente, como serviço de relevância pública.

Em uma análise mais geral sobre o Direito à Saúde na Constituição, o professor Luís Roberto Barroso (12) classifica-o como norma constitucional definidora de direitos. Segundo o atual Ministro do Supremo Tribunal Federal estas normas criam para seus beneficiários situações jurídicas imediatamente desfrutáveis, a serem materializadas em prestações positivas ou negativas. E caso as prestações não sejam satisfeitas, pelo Estado ou por quem tenha o dever jurídico de realizá-las, tem-se a possibilidade de seus destinatários postularem seu cumprimento, inclusive por meio de ação judicial. Assim, se

\footnotetext{
19 "Art. 23. É competência comum da União, dos Estados, do Distrito Federal e dos Municípios: II - cuidar da saúde e assistência pública, da proteção e garantia das pessoas portadoras de deficiência; "

20 "Art. 24. Compete à União, aos Estados e ao Distrito Federal legislar concorrentemente sobre: XII - previdência social, proteção e defesa da saúde; " (grifo nosso).

21 "Art. 197. São de relevância pública as ações e serviços de saúde, cabendo ao Poder Público dispor, nos termos da lei, sobre sua regulamentação, fiscalização e controle, devendo sua execução ser feita diretamente ou através de terceiros e, também, por pessoa física ou jurídica de direito privado".
} 
ratifica, de forma incisiva, o direito subjetivo, ou seja, o poder de ação, de exigir a satisfação de um determinado interesse.

Complementando a afirmação anterior e, ao mesmo tempo, fornecendo um direcionamento inovador, a professora Maria Célia Delduque (13) advoga que o direito à saúde também deva ser efetivado não somente pelos meios tradicionais de judicialização da saúde (ações judiciais via processos), mas também por Modelos Alternativos de Resolução de Conflitos (Marc) tal qual a Mediação Sanitária como novo paradigma para a efetivação da política pública de saúde no Brasil ${ }^{22}$.

O paradigmático art. 196 da Constituição Federal produziu balizadoras jurisprudências no Supremo Tribunal Federal (STF), como o Agravo de Regimento no Recurso Extraordinário ํㅜ $271286^{23}$ que sistematizou a matéria junto à Corte máxima do seguinte modo:

O direito público subjetivo à saúde representa prerrogativa jurídica indisponível assegurada à generalidade das pessoas pela própria Constituição da República (art.196). Traduz bem jurídico constitucionalmente tutelado, por cuja integridade deve zelar, de maneira responsável, o Poder Público, a quem incumbe formular - e implementar políticas sociais e econômicas idôneas que visem a garantir aos cidadãos o acesso universal e igualitário à assistência farmacêutica e médicohospitalar.

Corroborando a relevância do direito à saúde, a professora Sueli Dallari (14) afirma que sua eficácia e implementação vem sendo fortalecidos ao longo dos anos em virtude da forte característica de participação popular em sua construção e sua estruturação como um sistema de saúde pois, ao contrário de outros direitos sociais constitucionalizados, o direito à saúde "tem sua garantia claramente vinculada às políticas sociais e econômicas, as diretrizes do sistema expressamente formuladas, envolvendo a participação da comunidade..." (p.11 2008/2009).

Por fim, não podemos deixar de sublinhar a complexidade e profundidade da estruturação e efetivação do direito à saúde por meio do SUS, abarcando vários campos do saber numa intensa interdisciplinaridade, como ressalta a pesquisadora Sandra Alves

\footnotetext{
22 Para aprofundamento do acesso à justiça e seus modernos desdobramentos, consultar Delduque (2015). Disponível em http://www.conass.org.br/biblioteca/pdf/colecao2015/CONASS-DIREITO_A_SAUDE-ART_9B.pdf Acesso em 11 de junho de 2017.

23 Agravo de Regimento no Recurso Extraordinário $271286 . \quad$ Disponível em http://www.stf.jus.br/portal/diarioJustica/verDiarioProcesso.asp?numDj=226\&dataPublicacaoDj=24/11/2000\&incidente=35 42020\&codCapitulo=5\&numMateria=37\&codMateria=3 Acesso em 10 de junho de 2017.
} 
(15) que "na atual sociedade contemporânea, não é possível falar em direito à saúde sem considerar questões sociais, econômicas, territoriais, políticas, tecnológicas etc." (p.4, 2015).

E sobre a complexidade da interpretação hermenêutica do direito à saúde - apesar da importância da interpretação normativo-constitucional - há a observação de que o direito à saúde "...é um direito complexo, que demanda intervenções e produção de conhecimento igualmente complexos" (p.3) (16). Dessa forma, segundo a professora Sílvia Badim Marques (16):

“...para a garantia do direito à saúde é preciso que o operador do direito conheça não só o texto normativo, mas também o contexto em que este direito se insere. É preciso que conheça as muitas implicações que seus atos podem ocasionar no plano político, econômico e médico-sanitário e, para tanto, a ciência jurídica precisa avançar para além do estrito paradigma positivista de aplicação e produção do direito". (2015, p.3)

Portanto, como constatamos, a efetivação do direito à saúde na Constituição brasileira foi resultado de muita luta democrática, com participação popular, formação técnica e política, cooperação interfederativa, financiamento, ativismo jurídico, políticas sociais e econômicas, no intuito de materializar a concepção integral do complexo Sistema Único de Saúde, base fulcral da militância sanitarista.

\section{Os anos 1990: as políticas públicas de saúde no contexto neoliberal no Brasil}

\section{O direito à saúde no governo Collor: introduzindo o neoliberalismo}

Na década posterior, de 1990, o movimento sanitário brasileiro enfrentou um desafio: colocar em prática o arcabouço progressista do SUS numa conjuntura adversa se comparável à década anterior, com a crise ideopolítica dos valores progressistas e o advento do neoliberalismo ${ }^{24}$ e suas políticas de ajuste, cortes, demissões e privatizações, representado pelo Governo Collor (1990-1992).

Era necessário a regulamentação dos artigos que diziam respeito à saúde pública da Constituição (arts.196 a 200), que descreviam aspectos importantes para a política pública

24 Doutrina sistematizada por economistas da Escola Austríaca e de Chicago que pregavam mínima intervenção do Estado, controle da inflação, ataque a sindicatos e outros tipos de organizações de trabalhadores, austeridade fiscal, desregulamentação e favorecimento ao mercado, principalmente ao capital fictício-especulador das bolsas de valores. (SADER;GENTILI, 2008). 
via SUS, tais como: universalidade, integralidade, gratuidade, relevância pública, descentralização, direção única, municipalização, entre outros.

Em 19 de setembro de 1990, foi aprovada pelo Congresso Nacional a Lei Orgânica da Saúde (LOS), lei no $8.080^{25}$, que consolidava os objetivos, princípios e diretrizes do SUS, ampliando a responsabilidade comum e solidária dos entes na efetivação dos serviços, programas e projetos, alocação de recursos financeiros e humanos, garantia e proteção do direito à saúde aos mais diversos segmentos como trabalhadores e indígenas, participação democrática via conselhos e conferências, além de outros avanços da pauta do Movimento Sanitário.

Porém, coerente com seu governo neoliberal de restrição democrática e social, o presidente Collor sancionou a Lei Orgânica da Saúde com nove vetos que impactaram de forma direta as principais conquistas do movimento sanitário, como por exemplo: veto sobre o financiamento da saúde pelo Estado, em seus três níveis de Governo e pelo conjunto da sociedade; veto sobre a participação democrática da sociedade via conselhos paritários que fiscalizariam os recursos repassados; veto sobre a não extinção do Instituto Nacional de Assistência Médica da Previdência Social - INAMPS, veto sobre o plano de carreira, de cargos e salários (PCCS) dos servidores do SUS, entre outros retrocessos.

O Movimento Sanitário, ainda coeso e influenciado pelo ascenso de lutas da década de 1980, se reorganizou e lutou conjuntamente pela reversão dos pontos vetados pelo presidente Collor. Este, que havia subestimado o poder de organização do Movimento, teve que recuar três meses depois e obrigado a sancionar a Lei no 8.142, de 28 de dezembro de $1990^{26}$, reestabelecendo, mesmo que parcialmente ${ }^{27}$, o conteúdo que havia sido vetado.

Esse embate entre os retrógrados vetos de Collor e, por outro lado, a recuperação de parte significativa do texto original da lei $n^{\circ}$ 8.080, de 1990, representando o projeto da Reforma Sanitária, originaram no Brasil talvez o único exemplar conhecido de uma lei orgânica de uma determinada política social (em nosso caso, a saúde) que, na verdade, se constitui de duas leis. Apesar de alguns estudiosos do direito sanitário considerarem em seus escritos a Lei Orgânica da Saúde (LOS) como apenas a lei original 8.080/90, temos

\footnotetext{
${ }^{25}$ Disponível em http://www.planalto.gov.br/ccivil_03/leis/L8080.htm Acesso em 11 de junho de 2017.

26 Disponível em http://www.planalto.gov.br/ccivil_03/leis/L8142.htm Acesso em 11 de junho de 2017.

27 O Plano de Carreiras, Cargos e Salários - PC CS, por exemplo, não foi regulamentado, representando um retrocesso considerável frente ao Movimento Sanitário.
} 
que considerar os vetos reacionários que a amputaram e toda a mobilização que conseguiu reestabelecer o texto original com a lei 8.142/90 e, por fim, concluir que a Lei Orgânica da Saúde (LOS) é composta por duas leis: a lei 8.080/90, que devia ser aprovada em toda sua integralidade e a lei 8.142/90, aprovada três meses depois, com a marca da resistência e mobilização em torno das bandeiras iniciais da Reforma Sanitária.

\section{O direito à saúde nos governos FHC: o neoliberalismo clássico}

Já nos Governos Fernando Henrique Cardoso - FHC (1994-2002), os retrocessos sanitários continuaram com uma proposta privatizante bem mais estruturada e com o apoio da grande mídia, esta cumprindo o papel de aparelho ideológico do Estado - AIE (17) influenciando subjetivamente a consciência da população e até mesmo de representantes dos trabalhadores, como em sindicatos e associações, que deixaram de lutar por uma política pública de saúde e começaram a negociar planos privados para suas respectivas categorias.

O modelo implementado pelo ministro da Administração Federal e Reforma do Estado Bresser Pereira, como ideólogo do Plano Diretor da Reforma do Estado (PDRE) e partícipe do Consenso de Washington e do Banco Mundial ${ }^{28}$ era fomentar a privatização da saúde com medidas como a focalização individualizante via desestruturação dos serviços de saúde, como corte de gastos, terceirização de funcionários e de serviços e capitalização das empresas multinacionais do setor.

As práticas neoliberais na saúde são contrárias a princípios como os da universalidade, ao centrar ações focalizadas oferecendo uma saúde pobre para os pobres; contra a integralidade, ao priorizar a atenção básica de saúde, um mínimo existencial para o básico sanitário; contra a igualdade, ao seccionar de forma desigual os que têm condições de pagar pelo atendimento via plano privado e os que dependem exclusivamente do SUS; e contra o controle público via conselhos e conferências populares sendo subsumido nas regras privadas do mercado, com apoio de agências reguladoras flexíveis ao lobby privatista (18).

\footnotetext{
28 O Banco Mundial produziu dois documentos basilares para a década de 1990, com o propósito de frear o SUS e acelerar a privatização do setor: "Brasil: novo desafio à saúde do adulto", de 1991 e que teve pouca influência decorrente da turbulenta conjuntura do Governo Collor e "A Organização, Prestação e Financiamento da Saúde no Brasil: uma agenda para os anos 90", de 1995, este sim de grande influência no Governo FHC. (RIZZOTTO, 2012).
} 
Algumas iniciativas jurídico-institucionais foram cruciais para a tentativa de implementação do projeto neoliberal da saúde pública nos Governos FHC: a Norma Operacional Básica de 1996 (NOB/96), as Organizações Sociais (OS's) e as Organizações da Sociedade Civil de Interesse Público (OSCIP's); e o Programa Saúde da Família (PSF), conjuntamente com o Programa de Agentes Comunitários de Saúde (PACS).

A NOB $/ 96^{29}$ defende uma mudança no modelo de atenção à saúde, priorizando as ações sanitárias a partir da comunidade e, principalmente, tendo como foco a família, sem realçar as desigualdades sociais e o abismo que separa as classes mais favorecidas das mais pauperizadas, embutindo uma característica pós-moderna ${ }^{30}$ na política pública de saúde, contrária às noções dos condicionantes e determinantes que influenciam o aspecto sanitário das populações, interpretando apenas formalmente as condições epidemiológicas.

As Organizações Sociais (OS's) e as Organizações da Sociedade Civil de Interesse Público (OSCIP's) foram implementadas formalmente pelas leis nº 9.637/9831 e 9.790/9932 e fazem parte de uma nova forma de gestão sanitária, seguindo as diretrizes do Plano Diretor da Reforma do Estado (PDRE), instrumento basilar do neoliberalismo da década de 1990 no Brasil, com o intuito de transferir para as mãos da iniciativa privada o serviço público de saúde. (19).

Tanto as OS's quanto as OSCIP's podem, em determinados casos, contratar funcionários sem a obrigatoriedade de realização de concursos públicos, não necessitando de licitação para adquirir bens e serviços e sem prestar contas a órgãos de controle internos e externos, num retrocesso explícito não somente a todas as conquistas do projeto da Reforma Sanitária como também ao Estado Democrático e Social de Direito. Além disso, as OS's têm seu financiamento bancado pelo Estado numa transferência do fundo público para a administração privada, o que resulta num flerte constante com corrupção e desvio de verbas.

Dessa forma, com a implementação das OS's e OSCIP's no campo da política sanitária, houve uma violação constitucional pró-neoliberalismo no Brasil, pois o sistema

\footnotetext{
29 Disponível em http://bvsms.saude.gov.br/bvs/saudelegis/gm/1996/prt2203_05_11_1996.html Acesso em 11 de junho de 2017.

30 Pós-moderno aqui no sentido de relativizar a questão social no âmbito sanitário, negando-se a considerar as classes sociais e os aspectos políticos, econômicos e sociais que caracterizam a conjuntura sanitária do período.

${ }^{31}$ Disponível em http://www.planalto.gov.br/ccivil_03/leis/L9637.htm Acesso em 11 de junho de 2017.

32 Disponível em http://www.planalto.gov.br/ccivil_03/leis/L9790.htm Acesso em 11 de junho de 2017.
} 
privado só poderia atuar na saúde de forma complementar, conforme art. 199 da Constituição ${ }^{33}$, e hodiernamente atua de forma praticamente prioritária com a interação da gestão administrativa das fundações privadas num âmbito que antes era de alçada pública fomentando uma concorrência entre as organizações com base na relação demanda-lucro.

Por último, analisa-se o Programa Saúde da Família (PSF), juntamente com o Programa de Agentes Comunitários da Saúde (PACS) ${ }^{34}$. Tais programas iniciam no Brasil o caminho desenhado pelo Banco Mundial e pela Organização Panamericana da Saúde (OPAS) no intuito de focalizar a saúde em comunidades carentes e necessitadas de um mínimo de estrutura, com foco no atendimento à família.

Mas devemos ter cautela ao analisá-los pois a Política Nacional de Atenção Básica atua em torno da junção entre os princípios da universalidade e da equidade do SUS, característica da Estratégia Saúde da Família, juntamente com seus Agentes Comunitários da Saúde. Universalidade no sentido de propiciar tanto o aspecto preventivo quanto o curativo prioritariamente para a população que mais necessitava de atendimento, sem olvidar de toda a população que procurasse o serviço via SUS; e equidade no sentido material difundido no enunciado "tratar desigualmente os desiguais na medida de sua desigualdade". Dessa forma, há uma interpretação mais contraditória em relação a esses Programas que, a depender da conjuntura juspolítica, podem ser de caráter progressista ou não.

Finalizando a análise sobre as ações das políticas públicas de saúde no decorrer da década de 1990 no Brasil, constatamos que o Movimento da Reforma Sanitária, apesar da difícil conjuntura enfrentada, obteve algumas vitórias importantes, como a manutenção de uma Lei Orgânica da Saúde, a implementação da estrutura do SUS em todo o território nacional, a ratificação dos Conselhos e de Conferências de Saúde, a Política Nacional de Atenção Básica, uma vigilância epidemiológica e sanitária exemplar, além de outras conquistas.

Mas também sofreu com os retrocessos sanitários da conjuntura neoliberal tais como focalização como limite de atuação, incentivos ao complexo médico-industrial-financeiro via

\footnotetext{
${ }^{33}$ Art. 199. A assistência à saúde é livre à iniciativa privada. $§ 1^{\circ}$ As instituições privadas poderão participar de forma complementar do sistema único de saúde, segundo diretrizes deste, mediante contrato de direito público ou convênio, tendo preferência as entidades filantrópicas e as sem fins lucrativos (grifo nosso).

34 Portaria ํㅡ 2.488, de 21 de outubro de 2011, do Ministério da Saúde, que "aprova a Política Nacional de Atenção Básica, estabelecendo a revisão de diretrizes e normas para a organização da Atenção Básica, para a Estratégia Saúde da Família (ESF) e o Programa de Agentes Comunitários de Saúde (PACS)".
} 
desonerações e isenções fiscais, refilantropização, desprofissionalização como consequência de terceirizações e restrição dos objetivos, princípios e diretrizes do SUS; fortalecendo, desta forma, uma contrarreforma sanitária ligada aos setores privatistas e mercadológicos.

\section{Os anos 2000: o direito à saúde nos governos Lula e Dilma: auge e declínio do Partido dos Trabalhadores}

Havia muita expectativa em relação aos Governos do Partido dos Trabalhadores sobre as políticas públicas de saúde no Brasil. Várias análises sobre a possível retomada do projeto original da Reforma Sanitária foram realizadas, pois o setorial de saúde do PT era formado por alguns construtores do Movimento Sanitário, que intercalavam sua militância com instituições históricas como o Cebes e a Abrasco.

A disputa que se deu pós-Constituição no Brasil dirigia-se, basicamente, em torno de dois projetos sanitários, o primeiro em defesa dos princípios, diretrizes e objetivos do Sistema Único de Saúde (SUS) e o segundo em defesa da privatização via transformação do espaço de atuação complementar da saúde em prioritário, desconstruindo os alicerces da Reforma Sanitária.

Há uma disputa de narrativas em torno da política pública de saúde nos governos do Partido dos Trabalhadores (PT). Alguns intelectuais, como Telma Maria Menicucci (20) e Ana Maria Costa (21) defendem como avançada a política sanitária, principalmente se levarmos em consideração os condicionantes da saúde e não somente o aspecto endógeno, apesar de tecerem críticas pontuais. E outros intelectuais, como Maria Inês Bravo (22), Franciso Batista Jr. (23), Lígia Bahia e Mário Scheffer (24) defendem que houve um retrocesso sanitário com o transformismo (25), crise de direção e consequente burocratização do PT, refletindo diretamente na implementação da política pública de saúde no período.

\section{Argumentos favoráveis às políticas públicas de saúde nos governos do PT}

As pesquisadoras Telma Menicucci (20) e Ana Costa (21) elencam as principais ações no campo da saúde nos dois Governos Lula (2003-2010). No primeiro mandato (2003-2006) as autoras destacam as seguintes iniciativas e proposições: a Política de Saúde Bucal via Programa Brasil Sorridente, que Menicucci destaca como inédita e 
aprofundada em seu nível de expansão já que, entre 2002 e 2006 as equipes de saúde bucal dão um salto quantitativo de 4.260 para 14.244 , atendendo quase 70 milhões de pessoas em grotões do Brasil; sobre este fato parece que a autora acredita na lei da dialética da transformação da quantidade em qualidade, pois sublinha como um avanço complementar dessa política a instalação de aproximadamente 500 centros de especialidades e laboratórios regionais de próteses dentárias.

As autoras também destacam o atendimento pré-hospitalar móvel via Política de Atenção às Urgências e Emergências por meio do Serviço de Atendimento Móvel de Urgência (SAMU) e o Programa Farmácia Popular, que permite um desconto de até $90 \%$ dos medicamentos por meio do subsídio governamental, favorecendo principalmente os idosos, que são os maiores consumidores de medicamentos.

Há também a valorização da atenção básica de saúde, sem tecer nenhuma crítica, pelo contrário, flertando com as determinações do Banco Mundial sobre "universalismo básico"35 ao defender veladamente a focalização da atuação sanitária pelo Estado brasileiro ao elencar um acréscimo de $57 \%$ do número de equipes de saúde, aumento de recursos do Piso de Atenção Básica, que passou de $R \$ 10,00$ (valor estancado desde 1988) para $R \$ 15,00$ e a construção dos Centros de Atenção Psicossocial (CAPS), entrando num novo rumo da Reforma Psiquiátrica.

Avanços foram destacados, segundo as autoras, na questão dos medicamentos, com a criação da Câmara de Regulação do Mercado de Medicamentos (CMED) ${ }^{36}$, 0 aprofundamento da política de medicamentos genéricos e a realização da $1^{\text {a }}$ Conferência Nacional de Medicamentos e Assistência Farmacêutica.

No segundo mandato do Governo Lula (2007-2010), afinado com as discussões sobre o denominado "neodesenvolvimentismo" ${ }^{37}$, o Governo entra numa nova política de saúde baseada em uma espécie de "neodesenvolvimentismo sanitário", com ênfase no

\footnotetext{
35 A autora defende o ponto de vista de Filgueira et al. (2006, P.17) em documento elaborado para o Banco Interamericano de Desenvolvimento (BID): "El universalismo básico es un concepto que se implementa gradual y progresivamente en cada país, con redefiniciones sistemáticas del conjunto de las prestaciones básicas así como del alcance de cada una de ellas, que permiten ir asegurando, a través del tiempo, el cumplimiento de sus objetivos y fines". ${ }^{36}$ Criada pela Lei oㅜ 10.742, de 6 de outubro de 2003, a CMED é um órgão interministerial responsável por regular o mercado e estabelecer critérios para a definição e o ajuste de preços, tendo a Agência Nacional de Vigilância Sanitária ANVISA como Secretaria Executiva. Disponível em http://portal.anvisa.gov.br/cmed Acesso em 18 de junho de 2017.

37 Com medidas como o Programa de Aceleração do Crescimento (PAC), o programa habitacional Minha Casa Minha Vida, projeto geoestratégico de soberania a partir do Pré-Sal, entre outras iniciativas favorecidas pelo "boom" das commodities, intelectuais próximos ao Governo sistematizaram a tese segundo a qual o segundo mandato do Governo Lula estava inaugurando um novo desenvolvimentismo no Brasil, trazendo uma ideia revitalizada dos anos 1960/1970.
} 
incentivo via subsídios e desonerações do complexo médico-hospitalar, com o argumento de que a saúde movimentava consideráveis $8 \%$ do Produto Interno Bruto (PIB). O Governo, ciente da importância dessa política, cria, no ano de 2007, o Programa de Aceleração do Crescimento (PAC) da Saúde, intitulado oficialmente de Programa Mais Saúde, com o intuito de movimentar a economia sanitária, baseado no emprego, renda e na construção de empresas públicas, como a Empresa Brasileira de Hemoderivados e Biotecnologia (Hemobrás), com a liderança do Ministério da Saúde (21).

Além do PAC da saúde, há a expansão da Estratégia Saúde da Família (ESF) com a criação de 2.500 novas equipes entre os anos de 2007 e 2008 e, que, para melhorar a estrutura destas, o Governo incentivou a criação dos Núcleos de Apoio à Saúde da Família (NASF's) (20).

Por fim, arrematando as contribuições positivas, os principais avanços da política de saúde do Governo Lula foram as melhorias dos fatores condicionantes e determinantes da saúde com a série de programas de transferência de renda com suas contrapartidas e valorização do salário mínimo, além de aumento do mercado formal de trabalho, que contribuíram para a diminuição da mortalidade infantil e melhorias em vários indicadores epidemiológicos da saúde, como segurança alimentar e renda (20) (21).

\section{Argumentos críticos às políticas públicas de saúde nos governos do PT}

Por outro lado, destacando as críticas aos governos do PT, os militantes e intelectuais Maria Inês Bravo (22), Francisco Batista Jr.(23), Lígia Bahia e Mário Scheffer (24) destacam a continuidade da contrarreforma sanitária pelo Governo Lula, priorizando o privatismo sanitário com ações focalizadas, seguindo os padrões de organismos internacionais e incentivando o mercado de planos privados de saúde, com a apresentação de uma baixa regulação realizada pela Agência Nacional de Saúde Suplementar (ANS) e pouca valorização das discussões e resoluções dos conselhos (principalmente o Conselho Nacional de Saúde - CNS) e das Conferências realizadas.

Os Governos do PT continuaram priorizando uma saúde pública focalizada, principalmente para o segmento mais hipossuficiente da sociedade. Este segmento que faz uso do SUS, apesar de relevante em termos quantitativos, não está organizado em instituições, movimentos ou sindicatos formalizados onde possam expressar suas 
reivindicações e denúncias, transformando-se num bloco fragmentado e disperso, não influenciando as políticas sanitárias do Governo (22).

Para agravar essa situação, os sindicatos que se situam na órbita do PT, formado por categorias profissionais influentes (professores, bancários, servidores públicos, metalúrgicos) não estão lutando mais pelo Sistema Único de Saúde (SUS), mas sim negociando com o patronato a filiação aos melhores planos privados de saúde, assim também ocorrendo com os gestores públicos, enfraquecendo ainda mais a luta pela permanência da efetivação do SUS.

Também há o aprofundamento da implantação de uma gestão gerencial, a la Bresser ${ }^{38}$, com a continuidade de subsídios por meio do fundo público às OS's e OSCIP's, com a criação de mais Fundações e completa privatização de hospitais universitários sob administração da Empresa Brasileira de Serviços Hospitalares (EBSRH), ferindo a Constituição, a Consolidação das Leis Trabalhistas (CLT) e, especificamente, a autonomia universitária. Essas concessões e permissões afrontam também a estabilidade e a melhoria das condições de trabalho dos recursos humanos do SUS, aumentando a precarização e a terceirização (22).

Outro retrocesso social em relação às políticas públicas de saúde nesse período refere-se ao subfinanciamento que foi, lamentavelmente, aprofundado pelos Governos do PT. Com a extinção da CPMF $^{39}$ em 2007, o Governo e o Movimento Sanitário reiniciaram a discussão sobre a regulamentação da Emenda Constitucional (EC) 29/200040 que assegurava a participação dos três níveis de Governo no financiamento do SUS a partir da definição de um percentual mínimo de recursos por ano. A regulamentação realizada no início de 2012 consolidou os investimentos da União, Estados e Municípios. Os Estados continuam obrigados a investir, no mínimo, 12\% da arrecadação dos impostos, enquanto os Municípios, 15\%. O Distrito Federal investirá de 12 a 15\%, conforme a classificação da fonte da receita em estadual ou distrital. Mas a maior frustração do Movimento Sanitário em torno desta regulamentação foi o veto presidencial aos 10\% da Receita Corrente Bruta

\footnotetext{
${ }^{38}$ Ministro de FHC que implementou uma administração gerencial com foco no corte de verbas e enxugamento da máquina pública, como analisamos anteriormente.

39 Contribuição Provisória sobre a Movimentação ou Transmissão de Valores e de Créditos e Direitos de Natureza Financeira, simplificada como Contribuição Provisória sobre Movimentação Financeira - CPMF.

40 Disponível em http://www.planalto.gov.br/ccivil_03/constituicao/emendas/emc/emc29.htm Acesso em 24 de junho de 2017.
} 
(RCB) da União, o que dificultaria a consolidação do financiamento público da saúde universal e integral de acordo com nossa Constituição (23).

Destacamos também que o Brasil é o único país do mundo de sistema universal onde os investimentos privados superam os investimentos públicos. Estima-se que o investimento total em saúde (tanto público quanto privado) é de atualmente $9 \%$ do Produto Interno Bruto (PIB), ficando abaixo dos Estados Unidos que investem 15\%, mas mais próximo dos países membros da Organização para Cooperação e Desenvolvimento Econômico (OCDE) que possuem sistema universal como Inglaterra (8,4\%), Espanha (8,5\%), Austrália (8,98\%) e Canadá $(10,1 \%)(26)$.

O problema do Brasil é que o investimento público é bem abaixo do privado, enquanto o primeiro está em torno de $45-47 \%$, o segundo alcança até $55 \%$ (26) fato inédito em país com sistema universal de saúde e que já alcançou a posição de sétima maior economia do mundo ${ }^{41}$.

Passando à análise do primeiro Governo Dilma Rousseff (2011-2014), assim como nos Governos Lula, foi secundarizado o projeto da Reforma Sanitária frente ao Projeto Privatista da Saúde, de modo que os governantes do Partido dos Trabalhadores pudessem colocar em pauta as promessas com seus financiadores de campanha, majoritariamente do alto empresariado da saúde com empreendimentos de complexos médico-hospitalaresfinanceiros ${ }^{42}(24)$.

As manifestações de junho de 2013, que mobilizaram a pauta política do país, colocaram a saúde pública no topo das propostas, com frases irreverentes típicas de um movimento liderado pela juventude como, por exemplo, "enfia os 20 centavos no SUS" 43 e "queremos saúde padrão FIFA"44. Manifestações na periferia do Brasil, principalmente nas favelas ditas "pacificadas" do Rio de Janeiro se destacaram pela vanguarda na defesa da saúde pública, especificamente por um investimento do Governo no saneamento como prioridade, como foi o caso dos moradores da Rocinha, que exigiram melhorias sanitárias

\footnotetext{
${ }^{41}$ Atualmente, o Brasil caiu para a nona economia do mundo.

42 Em estudo realizado por Scheffer e Bahia (2011), o PT foi o terceiro partido que mais recebeu aportes financeiros das operadoras de planos de saúde na campanha de 2010: 14,05\% do total, só ficando atrás do PMDB (28,94\%) e do PSDB $(18,16 \%)$. Analisando especificamente a eleição presidencial, a então candidata Dilma Roussef (PT) recebeu o dobro do seu adversário, o tucano José Serra: $R \$ 1000.000$ da Qualicorp Corretora de Seguros contra R $\$ 500.000$ para Serra (PSDB). Disponível em http://www.cebes.org.br/media/File/Planos_de_Saude_Eleicoes.pdf. Acesso em 1ํ de junho de 2017.

43 Numa referência, à época, ao aumento de 20 centavos no preço das passagens do transporte público em algumas capitais, como em São Paulo.

${ }^{44} \mathrm{Em}$ referência aos estádios para a Copa do Mundo de 2014 que tinham que ser "padrão FIFA".
} 
ao invés do Governo priorizar o teleférico para transporte de turistas na mesma comunidade $^{45}$.

A resposta de Dilma em relação aos protestos de junho que pediam mais investimento em saúde foi o Programa Mais Médicos ${ }^{46}$, instituído pela Lei nำ12.871/2013, que se baseia na importação de médicos estrangeiros para trabalharem nos grotões mais distantes do país, principalmente nas mais de 400 cidades em que não havia atuação de nenhum médico, por meio de uma bolsa paga pelo Governo brasileiro. Apesar de ser um programa progressista e de alta popularidade, alguns membros da área da saúde criticaram a proposta por não tocar nos aspectos estruturais da saúde pública, como financiamento, condições de trabalho, falta de medicamentos, entre outros.

O segundo mandato de Dilma (2015-2016) ${ }^{47}$ iniciou envolto em polêmicas em relação à área de saúde, com a apresentação de programas como o Mais Especialidades, que seria uma segunda etapa do Programa Mais Médicos, com acesso da população a tratamentos com médicos especialistas, utilizando estruturas dos próprios hospitais públicos, entidades filantrópicas e até da rede privada e há também uma priorização do segundo mandato de Dilma ao favorecimento do complexo médico-industrial-financeiro com a aprovação de Medida Provisória ${ }^{48}$ que permite entrada do capital financeiro internacional nas ações e serviços da saúde no Brasil.

Mas não houve tempo para uma análise de maior profundidade, pois o Governo Dilma Rousseff enfrentou uma espécie de "tempestade política perfeita" 49 que unia num mesmo período a crise econômica provocada pelo ajuste fiscal que gera principalmente desemprego e queda da renda; relação delicada com o Congresso Nacional mais

\footnotetext{
${ }^{45}$ Foi noticiada nos principais jornais do país a marcha de moradores da Rocinha e do Vidigal até o bairro nobre do Leblon para reivindicarem saneamento básico para as comunidades. Conferir em http://g1.globo.com/rio-dejaneiro/noticia/2013/06/rocinha-e-vidigal-marcharam-em-paz-ate-o-leblon-por-saneamento-e-saude.html Acesso em 1으 de julho de 2017.

${ }^{46} \mathrm{Em}$ apenas dois anos de atuação, o Programa Mais Médicos conseguiu levar 18.240 médicos a 4.058 municípios de 34 Distritos Especiais Indígenas (DSEI), beneficiando aproximadamente 63 milhões de pessoas. Atualmente, o Programa encontra-se esfacelado pelo Governo Temer.

$47 \mathrm{Em} 12$ de maio de 2016, foi afastada de seu cargo por até 180 dias devido à instauração de um processo de impeachment. Teve o mandato presidencial definitivamente cassado em 31 de agosto de 2016, porém não perdeu seus direitos políticos.

48 Medida Provisória no 656, de 7 de outubro de 2014, convertida na Lei o 13.097, de 19 de janeiro de 2015. Especificamente no Capítulo XVII - Da Abertura ao Capital Estrangeiro na Oferta de Serviços à Saúde (art. 142), alterando a Lei Orgânica da Saúde em seus arts. 23 e 53-A. Disponível em http://www.planalto.gov.br/ccivil_03/_ato20152018/2015/lei/l13097.htm Acesso em 18 de junho de 2017.

49 Expressão citada por cientistas políticos brasileiros, como o professor Marcus Melo, da Universidade Federal de Pernambuco (UFPE). Disponível em http://www1.folha.uol.com.br/poder/2015/02/1593286-tempestade-perfeita-ameacao-governo-dilma-diz-academico.shtml Acesso em 18 de junho de 2017.
} 
conservador das últimas décadas; denúncias de corrupção atingindo principalmente membros da cúpula diretiva do seu partido político (PT), assim como as principais empresas privadas do país e grandes empresas públicas, como a Petrobrás e Eletrobrás; e manifestações massivas de rua - com participação de setores conservadores e ultradireitistas que conseguiram tomar a direção de um processo de crise iniciado nas manifestações de junho de $2013^{50}$ - resultando em seu impeachment em agosto de 2016.

\section{O governo Temer: uma nota sobre o neoliberalismo de exceção}

Com a saída de Dilma Rousseff do poder, entrou em seu lugar o vice-presidente Michel Temer (PMDB) implementando a doutrina do choque e do pavor (27) e o estado de exceção (28), ambos elementos para uma espécie de conceituação que podemos classificar de "neoliberalismo de exceção" que se baseia nas seguintes características: ajuste fiscal rigoroso, agressiva perseguição e criminalização aos movimentos sociais, avanço das deformas ${ }^{51}$ trabalhista e previdenciária, apoio irrestrito ao setor privado via isenções, desonerações e incentivos financeiros ao mercado, controle e parceria com a maioria do congresso nacional, principalmente com as bancadas mais conservadoras, como as dos planos privados de saúde, da bala (armamento), da bíblia (evangélicos) e do boi (agronegócio), além de conchavos com a nata do setor bancário-financista, jurídico e midiático numa aliança contra tudo o que representa os termos Democracia, Direitos Humanos e Políticas Sociais no Brasil ${ }^{52}$.

\footnotetext{
50 As manifestações a favor do Impeachment no Brasil, durante o segundo mandato de Dilma Rousseff, radicalizaram-se por um viés nitidamente conservador, como o exemplo de manifestantes pedindo a volta da Ditadura Militar, como vimos nas massivas manifestação de 15 de março de 2015 e 13 de março de 2016 . Houve também grandes manifestações (18 de março de 2016) denunciando o impeachment como um golpe a uma presidente legitimamente eleita e que não cometeu crime de responsabilidade. Portanto, o impeachment - resultado da profunda crise que ainda hoje se alastra no país - não foi uma unanimidade, como aconteceu com o ex-presidente Fernando Collor. Conferir em https://fpaprod2.hacklab.com.br/wp-content/uploads/2015/03/fpa-pesquisa-manifestacoes.pdf Acesso em 18 de junho de 2017.

51 Usamos o termo contrarreforma (BEHRING, 2008) para os retrocessos sociais perpetrados pelos Governos que aplicam o ideário conservador em determinadas políticas como, por exemplo, a contrarreforma trabalhista e previdenciária. O termo contrarreforma é uma resposta contra a ressemantificação e banalização do termo "reforma" pois este conceito (reforma) deve ser respeitado como de uso da tradição da esquerda, principalmente da II Internacional de Bernstein e Kautsky, que eram reformistas no sentido progressista, de luta por melhorias graduais dos trabalhadores. Mas o termo que melhor definiria os ataques do conservadorismo contra os direitos sociais seria "deforma", já que não há nem reforma (que é um termo da esquerda) e nem contrarreforma (que seria uma dicotomia em relação à reforma) mas algo ainda mais grave, uma espécie de deformação das políticas sociais, ao tentar restringir ou até mesmo extinguir os direitos sociais e qualquer forma de desenvolvimento nos condicionantes e determinantes sociais. Portanto, o termo mais próximo dessa desconfiguração social seria "deforma".

52 Atualmente, o Presidente Michel Temer, Ministros de Estado, Deputados, Senadores, membros do Sistema de Justiça, além dos principais empresários do setor privado do país estão sendo denunciados em várias frentes de operações contra a corrupção. A mais famosa dessas operações é a denominada Operação Lava-Jato, criada desde 2014 e responsável por mais de 40 fases de investigação. O Brasil continua numa grave crise institucional, com o presidente
} 
Especificamente em relação à política pública de saúde, o Governo Temer enterrou de vez qualquer tipo de avanço na área acelerando a privatização e o subfinanciamento do setor defendendo propostas desconstituintes - no sentido de violar o SUS Constitucional a começar pela nomeação para Ministro da Saúde de um representante do conglomerado de empresas de planos privados de saúde. ${ }^{53}$

São vários os retrocessos sanitários perpetrados por apenas 1 ano de neoliberalismo de exceção aplicados no período Michel Temer e uma das principais iniciativas é a Proposta de Emenda Constitucional - PEC no 241 (Câmara dos Deputados) renumerada como $n^{\circ} 55$ (Senado Federal), que foi aprovada pelo Congresso Nacional como Emenda Constitucional no 95/2016, que institui o Novo Regime Fiscal ${ }^{54}$ e que retirará do SUS em torno de $R \$ 400$ bilhões de reais em 20 anos caso seja considerado o crescimento anual do Produto Interno Bruto - PIB a 2,0\% e a taxa de variação do Índice Nacional de Preços ao Consumidor Amplo (IPCA) em 4,5\% (VIEIRA;BENEVIDES, 2016). Será o fim do SUS como o conhecemos pois não haverá investimento real nas ações e serviços públicos de saúde (ASPS), sendo um ataque de graves proporções às propostas e demandas do Movimento da Reforma Sanitária.

Outro retrocesso sanitário é a proposta dos planos privados populares ou oficialmente denominado Plano de Saúde Mais Acessível realizada por um grupo de trabalho convidado pelo próprio Ministério da Saúde e formado por representantes de mais de 20 instituições ligadas à saúde suplementar, incluindo a Abrange (Associação Brasileira de Planos de Saúde), AMB (Associação Médica Brasileira), Unimed, além de representantes governamentais como a Agência Nacional de Saúde Suplementar (ANS), demonstrando, por parte do governo, uma postura inconstitucional e incoerente com seu dever de efetivação e comprometimento com o Sistema Único de Saúde. ${ }^{55}$

\footnotetext{
Michel Temer apresentando taxa de aprovação de apenas 7\%, enquanto a saúde e a corrupção lideram as preocupações dos brasileiros, conforme http://www1.folha.uol.com.br/poder/2017/06/1895645-aprovacao-da-gestao-temer-cai-a-7menor-em-28-anos.shtml Acesso em 24 de junho de 2017.

${ }^{53} \mathrm{O}$ atual Ministro da Saúde Ricardo Barros (PP/PR) quando candidato a deputado federal em 2014, recebeu sua maior doação individual (100 mil reais) das mãos de Elon Gomes de Almeida, sócio do Grupo Aliança, administradora de benefícios de saúde, num explícito conflito de interesses.

54 Disponível em http://www2.camara.leg.br/legin/fed/emecon/2016/emendaconstitucional-95-15-dezembro-2016-784029publicacaooriginal-151558-pl.html Acesso em 18 de junho de 2017.

55 As propostas de planos privados populares são as seguintes: a) plano simplificado: cobertura inclui atenção primária (atendimento não-especializado), consultas com especialistas e exames de diagnóstico de baixa e média complexidade. Não inclui internação, terapias e exames de alta complexidade nem atendimento de urgência e emergência; b) plano ambulatorial e hospitalar: cobertura inclui atenção primária e atenção especializada de média e alta complexidade, sendo que o atendimento com especialistas só é realizado mediante encaminhamento de um serviço básico de saúde; c) plano
} 
Há outros retrocessos sanitários do Governo Temer e seu neoliberalismo de exceção, como o corte de banda larga de milhares de Unidades Básicas de Saúde (UBS), suspensão de concursos públicos para o Ministério da Saúde, conflito sistemático com a Secretaria Especial de Saúde Indígena (SESAI), contingenciamento no repasse de financiamento para os entes subnacionais, fechamento de centenas de Farmácias Populares e redução de atuação do Programa Mais Médicos, explicitando, dessa forma, uma atuação juspolítica contrária aos ditames do SUS Constitucional.

\section{Considerações finais}

Vimos que a Nova República no Brasil, caracterizada pela redemocratização, resumiu-se, em sua maior parte, na disputa entre dois projetos antagônicos: da esquerda democrática e do setor centro-direitista-conservador. Depois da chegada ao poder desses dois polos ideológicos, sem nenhuma mudança estrutural que beneficiasse a maior parte da população, há uma sensação de desgaste dos mecanismos que permitem a governança via presidencialismo de coalizão.

Tais fatos também impactaram a saúde pública. De origem progressista e avançada, com uma normatização exemplar para o mundo, as políticas públicas aplicadas no âmbito sanitário tornaram-se reféns da fúria dos mercados financeiros que financiaram os principais candidatos a cargos eletivos, cobrando a fatura por meio da expansão da privatização do setor. O SUS tem sido sistematicamente relegado a um mecanismo residual de consolidação da focalização da saúde para uma população que, tragicamente, não apresenta condições de formar opinião e de influir nas manifestações do país.

Depois de mais de três décadas de redemocratização, de quase 30 anos de vigência da Constituição da República, de 7 eleições presidenciais e de uma alternância de poder entre os principais projetos pretensamente em disputa, que nos apresentaram a tímidos avanços e a desinibidos retrocessos na seara das políticas públicas, é chegada a hora de voltarmos a discutir se desejamos apenas transformações conjunturais, sem alterar a composição das classes sociais no Brasil, ou se almejamos transformações estruturais como a efetivação da Reforma Sanitária para que possamos cumprir com as diretrizes da nossa Carta Constitucional. 
Nesta lógica, urge imperioso que o Movimento Sanitário enfrente esta conjuntura de descenso e refluxo das lutas sociais em prol da defesa dos objetivos, diretrizes e princípios do SUS, patrimônio que reflete as conquistas do povo brasileiro. Para voltar a ser protagonista de um projeto de sociedade, o Movimento Sanitário precisa se reinventar, renovando e oxigenando suas práticas e atitudes e interligando-se com as principais questões que movimentam o país no plano dos direitos fundamentais sociais, em especial do direito sanitário.

\section{Referências}

1. Rother, ET. Revisão Sistemática x Revisão Narrativa. Acta Paulista de Enfermagem, São Paulo, 20 (2). Editorial. abr/jun 2007. Disponível em http://www.scielo.br/scielo.php?script=sci_arttext\&pid=S0103-21002007000200001 [Acesso em 30 jun 2017].

2. EscoreL, S. Reviravolta na Saúde: Origem e Articulação do Movimento Sanitário. Rio de Janeiro: Fiocruz, 1999.

3. Felipe, S. Projeto Montes Claros. Belo Horizonte: DAD/COC, 1993.

4.Tavares, D. de F. Projeto Montes Claros: Depoimento Oral. Belo Horizonte: DAD/COC, 1993.

5. Paim, JS. Reforma Sanitária Brasileira: contribuição para a compreensão e crítica. Salvador: Edufba; Rio de Janeiro: Fiocruz, 2008.

6. Luz, M.T. As Conferências Nacionais de Saúde e as Políticas de Saúde da Década de 80. In Guimarães, R.; Tavares, R. (Orgs). Saúde e Sociedade no Brasil: anos 80. Rio de Janeiro; Relumé Dumará,1994.

7.EscoreL, S; Bloch, R. História dos Trabalhadores da Saúde. In Ciência e Saúde Coletiva. 13 (3), Rio de Janeiro, maio/jun. 2008.

8. Moore JR, B. As Origens Sociais da Ditadura e da Democracia: senhores e camponeses na construção do mundo moderno. São Paulo: Martins Fontes, 1975.

9. Boschetti, I. Assistência Social no Brasil: um Direito entre Originalidade e Conservadorismo. Brasília: GESST/SER/UnB, 2003.

10. Araújo, LAD. O Conceito de Relevância Pública na Constituição Federal de 1988. In Revista de Direito Sanitário, São Paulo, 5 (2): 90-97, jul. 2004. 
11. Weichert, MA. A saúde como serviço de relevância pública e a ação civil pública em sua defesa. In ROCHA, João Carlos de Carvalho et al. (Orgs.). Ação Civil Pública - 20 Anos da Lei n. 7.347/85. Belo Horizonte: Del Rey, 2005. p. 507-531.

12. Barroso, LR. O Novo Direito Constitucional Brasileiro: contribuições para a construção teórica e prática. Belo Horizonte: Fórum, 2012.

13. Delduque, MC. A Mediação Sanitária como Novo Paradigma Alternativo à Judicialização das Políticas de Saúde no Brasil. In Para Entender a Gestão do SUS. Brasília: CONASS, 2015.

14. Dallari, S. A Construção do Direito à Saúde no Brasil. In Revista de Direito Sanitário. São Paulo: 9 (3): 9-34 Nov.2008/Fev.2009.

15. Alves, SMC. A Formação em Direito Sanitário: um diálogo possível a partir da interdicisplinaridade. In Para Entender a Gestão do SUS. Brasília: CONASS, 2015.

16. Marques, SB. Direito à Saúde: complexidade e enfrentamentos extrajudiciais. In Para Entender a Gestão do SUS. Brasília: CONASS, 2015.

17. Althusser, L. Aparelhos Ideológicos de Estado. Rio de Janeiro: Graal, 2007.

18. Gouveia, R; Palma, JJ. SUS: na Contramão do Neoliberalismo e da Exclusão Social. In Revista de Estudos Avançados. 43 (35), São Paulo Jan/Abr. 1999.

19 Granemann, S. Previdência Social: Da Comuna de Paris aos (Falsos) Privilégios dos Trabalhadores. In Navarro, Vera; Lourenço, Edvânia. (Orgs.). O Avesso do Trabalho. São Paulo: Outras Expressões, 2013.

20. Menicucci, TM. A Política de Saúde no Governo Lula. In Revista Saúde e Sociedade, 20 (2), São Paulo Abr/Jun. 2011.

21. Costa, AM. Saúde é Desenvolvimento. In SADER, Emir (Org.). 10 Anos de Governos Pós-Neoliberais no Brasil: Lula e Dilma. São Paulo: Boitempo; Rio de Janeiro: FLACSO Brasil, 2013.

22. Bravo, MI. Política de Saúde no Brasil. In MOTA, Ana Elisabete et al. (Org.) Serviço Social e Saúde: Formação e Trabalho Profissional. São Paulo: Cortez, 2009.

23. Batista JR, F. A Agonia do SUS. Disponível em http://fopspr.wordpress.com/2010/01/13/a-agonia-do-sus-por-francisco-batista-junior/. [Acesso em 10 jul 2017].

24. Bahia, L; Scheffer, M. Planos e Seguros Privados de Saúde. In GIOVANELLA, Lígia et al. Políticas e Sistema de Saúde no Brasil. Rio de Janeiro: Fiocruz, 2013. 
25. Gramsci, A. Maquiavel, a Política e o Estado Moderno. Rio de Janeiro: Civilização Brasileira, 1976.

26. Ocké-Reis, CA. Gasto Privado em Saúde no Brasil. In Cadernos de Saúde Pública V. 31, n.7 Rio de Janeiro: Jul/2015.

27. Klein, N. A Doutrina do Choque: a ascensão do capitalismo de desastre. São Paulo: Nova Fronteira, 2008.

28. AGambem, G. Estado de Exceção. São Paulo: Boitempo, 2007.

29. Vieira, FS; Benevides, RP de S. O Direito à Saúde no Brasil em Tempos de Crise Econômica, Ajuste Fiscal e Reforma Implícita do Estado. In Revista de Estudos e Pesquisas sobre as Américas. 10 (3) Brasília, 2016. 